\title{
Use of liothyronine in preventing electroconvulsive therapy-induced memory impairment: evaluation
}

\author{
Abbas Masoudzadeh, ${ }^{1,2}$ Seyyed Taha Yahyavi, ${ }^{1}$ Hooman Rashidi, ${ }^{1}$ Reza Ali Mohammadpour, ${ }^{1,3}$ \\ Reza Kiani ${ }^{4}$
}

The Psychiatrist (2013), 37, 49-53, doi: 10.1192/pb.bp.111.038398

\begin{abstract}
'Department of Psychiatry,
Mazandaran University of Medical Sciences, Sari, Iran; ${ }^{2}$ Psychiatry and Behavioral Sciences Research Center, Mazandaran University of Medical Sciences, Sari, Iran; ${ }^{3}$ Department of Biostatistics, Mazandaran University of Medical Sciences, Sari, Iran; ${ }^{4}$ Adult Learning Disability Services, Leicester Frith Hospital, Leicester, UK

Correspondence to Seyyed Taha Yahyavi (seyyedtaha@yahoo.com) First received 12 Jan 2012, final revision 22 Apr 2012, accepted 13 Jun 2012
\end{abstract}

\begin{abstract}
Aims and method To evaluate the effect of liothyronine administration on the cognitive side-effects of electroconvulsive therapy (ECT), 30 participants with major depressive disorder that were suitable candidates for ECT were randomly allocated to either a liothyronine or a placebo group. Participants in the liothyronine group received a daily $50 \mu \mathrm{g}$ dose for the whole period of receiving ECT starting the day before ECT, whereas the other group received a placebo. The Hamilton Rating Scale for Depression (HRSD) and the Wechsler Memory Scale - revised (WMS-R) were used for evaluating mood and memory before the first ECT session and after the sixth session (the HRSD was also used after the third session).
\end{abstract}

Results The results indicated that after the sixth ECT session, participants that received liothyronine achieved significantly better scores on the HRSD and WMS-R.

Clinical implications Further studies with a larger number of participants, through multicentre research projects, are indicated to obtain adequate data for meta-analysis and systematic review.

Declaration of interest None.
Electroconvulsive therapy (ECT) is recognised as an effective choice in the treatment of major depressive disorder. ${ }^{1}$ However, neurocognitive side-effects of ECT are well-known ${ }^{2-4}$ and have a negative impact on a patient's adherence with treatment. ${ }^{5}$ Several studies have been carried out in an effort to diminish these side-effects. ${ }^{6}$ Some concentrate on technical changes while administering $\mathrm{ECT}^{7-9}$ and others on add-on strategies. ${ }^{10,11}$ The use of thyroid hormones to prevent neurocognitive side-effects of ECT is one such add-on strategy. ${ }^{12-16}$ Although the effect of ECT on the hypothalamus-pituitary-thyroid axis is controversial, and conflicting findings have been reported, ${ }^{17-20}$ the fact that positive cognitive outcomes can be achieved by using thyroid hormone in conjunction with ECT is really promising and as such open to further investigation. The first studies to look at this were carried out around 20 years ago. ${ }^{12,14}$ Further evidence has confirmed these findings, ${ }^{13,15,16}$ and this was later reported in a textbook of psychiatry. ${ }^{21}$ However, there is still a lack of evidence and, as far as we could determine, there is no systematic review or meta-analysis on this subject in the medical literature. Some of the limitations of the previous studies were the small number of participants, use of ECT for different diagnostic categories and problems with methodology.

\section{Method}

\section{Study setting}

The study was granted ethical approved by the institutional review board of Mazandaran University of Medical Sciences and lasted from June 2010 to July 2011. It was carried out at Zare Mental Health and Burn Hospital, a tertiary psychiatric short-stay in-patient assessment and treatment unit in Sari (the capital city of Mazandaran province) located at the southern border of the Caspian Sea. It provides mental health services to a population of over three million in the northern area of Iran. Referrals are accepted mainly from Mazandaran province and neighbouring counties. Zare Hospital has a 12-bedded intensive care unit and a 40-bedded surgical department with two separate wards each for men and women. It provides emergency and cosmetic and reconstructive surgery for patients who sustain burn injuries either accidentally or through self-burning. The latter has been reported as a way of self-harm and suicide in Iran. ${ }^{22}$

Zare Hospital also has an integrated multi-agency mental health unit with facilities for 122 in-patient beds. These are divided into different gender-specific wards (59 general psychiatry beds for men, 27 general psychiatry beds for women, 8 child and adolescent beds, 8 addiction 
psychiatry beds). There are also 20 emergency beds for acutely ill patients requiring urgent admission due to aggressive behaviour or high risk of suicide. The ECT suite is open 3 days per week. The ECT team consists of an attending psychiatrist, a psychiatric resident, an anaesthetist, an anaesthetic technician and two psychiatric nurses. There is also a psychiatric out-patient department situated in the hospital grounds with the capacity to offer assessment for emergency and routine referrals. On average, 30-40 planned referrals and 10 emergency cases are seen in the out-patient clinic each day during working hours (08.00-16.00 h). Zare Hospital is a teaching centre, academically linked to the Medical School of the University of Mazandaran. The multidisciplinary team consists of psychiatric nurses, nursing assistants, speech and language therapists, physiotherapists, occupational therapists and social workers. The medical team consists of 10 attending psychiatrists, specialised in different disciplines (equivalent to the UK's consultant psychiatrist positions), 16 psychiatric residents of different grades (similar to specialty trainee year 1 (ST1) to ST6 psychiatric trainees) and up to 5 interns (similar to foundation year 1 (FY1) and FY2 trainees) providing $24 \mathrm{~h}$ cover including on-call coverage between the hours of 16.00 and 08.00. Additionally, there are around 15 medical students (fourth and fifth year) based at Zare Hospital each month during their psychiatric block. Each ward also has a clinical psychologist who carries out psychological assessments and provides therapy for patients.

\section{Inclusion and exclusion criteria and assessments}

Patients were recruited from those with severe treatmentresistant depression (not responding to at least two antidepressants of ideal dosage and duration) referred to Zare Hospital from mental health clinics in community and general practitioners' offices. These included patients who had to be admitted to Zare Hospital due to high suicide risk, severe psychomotor retardation or dehydration. We included patients, aged $18-60$ years, with a DSM-IV-TR ${ }^{23}$ diagnosis of major depressive disorder without psychotic features and a total 21-item Hamilton Rating Scale for Depression $(\mathrm{HRSD})^{24}$ score of at least 16 , with item 1 (depressed mood) scored 2 or greater. Indications for ECT were: serious suicidal ideation or attempts; severe psychomotor retardation; poor food and fluid intake.

The exclusion criteria were: any past or current thyroid disorder (including subclinical hypothyroidism, defined as a thyrotropin level above the upper limit of the normal range in the presence of normal $\mathrm{T}_{3}$ or $\mathrm{T}_{4}$ levels and in the absence of clinical signs or symptoms of hypothyroidism); a medical condition that could limit prescription of ECT or make liothyronine treatment unsafe; history of alcohol or other drug dependency or misuse in the preceding 12 months (except nicotine dependency); organic brain disease; history of cerebrovascular accident or increased intracranial pressure. Female patients who were pregnant or breastfeeding were also excluded.

\section{Assessments}

Potential referrals were assessed using DSM-IV-TR criteria for eligibility to take part in the study by a psychiatrist at their first clinic visit at Zare Hospital and only those who gave informed consent to receive ECT were included in the study. Baseline assessments included a comprehensive medical evaluation and blood tests for thyrotropin, total $\mathrm{T}_{3}$ and free $\mathrm{T}_{4}$ levels. The hormone levels were measured by immunoassay. Information was obtained regarding the history of depressive episodes and the course of the current episode, including antidepressant and other treatments received in order to confirm the diagnosis of treatmentresistant depression. Treatment with antidepressant medication during the current episode was regarded as adequate if the dose of antidepressants was optimum.

Severity of depression was assessed by HRSD before the first ECT session $\left(T_{1}\right)$, after the third session $\left(T_{2}\right)$ and 1 day after the sixth session $\left(T_{3}\right)$. Memory was assessed using the Wechsler Memory Scale - revised (WMS-R) ${ }^{25}$ before the first ECT session $\left(T_{1}\right)$ and again, 1 day after the sixth session $\left(T_{3}\right)$ in both control and test groups. The assessment was carried out by a psychologist who was masked to participants' allocation group.

\section{Group randomisation}

Eligible patients were randomly assigned to receive either ECT plus liothyronine (liothyronine group) or ECT plus placebo (placebo group). Randomisation was carried out by a medical statistician at the University of Mazandaran. Numbered treatment packages were supplied by a commercial pharmacist and were allocated according to sequential entry of patients into the protocol and based on the randomised list.

\section{Interventions}

Liothyronine $50 \mu \mathrm{g}$ tablets or placebo tablets (similar in size, weight and colour) were administered by nursing staff to the case and control groups 1 day before commencing ECT and on a daily basis for the duration of the study. The ECT was administered three times weekly over 2 weeks (six sessions) with hand-held electrodes. Methohexital (0.75$1.0 \mathrm{mg} / \mathrm{kg}$ ) was used for induction of anaesthesia and suxamethonium chloride $(0.5-1.0 \mathrm{mg} / \mathrm{kg})$ was used as a muscle relaxant. We used a Mecta SR2 device (Mecta Corp, Lake Oswego, Oregon, USA), which delivers constantcurrent, bi-directional brief pulses. The first electrical stimulus in the titration was set at $125 \mathrm{mC}$ so that a seizure of at least $25 \mathrm{~s}$ duration could be produced. If no seizure was witnessed, re-stimulations at intervals of $20-60 \mathrm{~s}$ were given in the same session, using progressively greater amounts of charge until a seizure was produced (seizure threshold). Subsequent treatments were given at 1.5 times seizure threshold for bilateral temporal ECT. The stimulus charge was titrated upwards as required during the treatment course (empirical titration method).

\section{Results}

Out of 57 eligible participants (based on DSM-IV-TR criteria for major depressive disorder, not responding to treatment with antidepressant medication), 22 could not be included because of our exclusion criteria (Fig. 1). In the liothyronine 


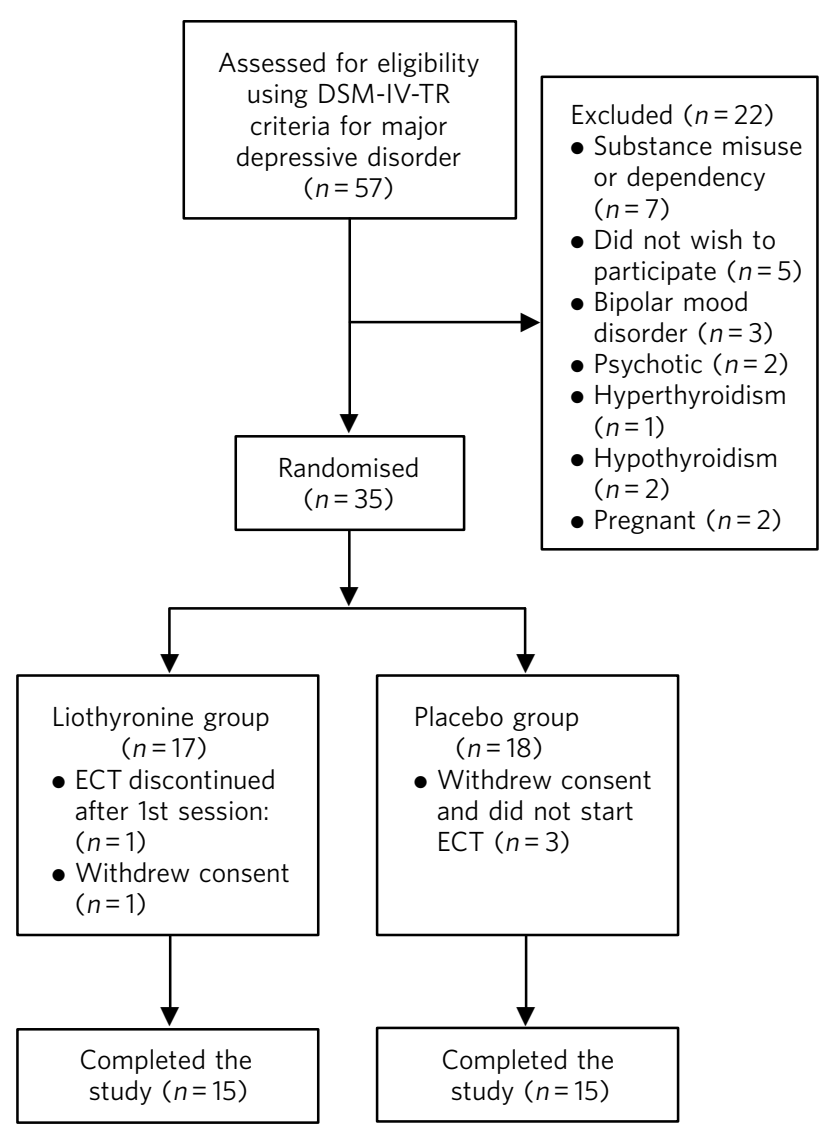

Fig 1 Flow chart of the progress through different stages of the trial. ECT, electroconvulsive therapy.

group one patient withdrew consent and one person suffered an arrhythmia after the first electroconvulsive session, therefore ECT was not continued. In the placebo group three patients withdrew their consent, hence, only data for 15 patients in each group were analysed.

The mean age of the participants was 38.17 years (s.d. = 11.11). The youngest participant was 20 and the oldest was 60. The liothyronine and placebo groups did not differ significantly in their demographic or clinical features (Table 1). All participants were taking at least one antidepressant at the recommended therapeutic dose for the duration of the study.

The scores of the two groups on both the HRSD and total WMS-R were not statistically different before starting ECT $\left(T_{1}\right)$. Independent sample $t$-tests indicated that the HRSD score was significantly lower in the liothyronine group than the placebo group after the sixth session of ECT $(P=0.025)$. This difference was not statistically significant after the third ECT session $\left(T_{2}\right)$. This was confirmed by carrying out the Mann-Whitney $U$-test $(P=0.024)$ (Table 2). Moreover, the total WMS-R score was significantly higher after the sixth ECT session in the liothyronine group based on independent sample $t$-tests $(P=0.033)$ and the Mann-Whitney $U$-test $(P=0.041)$ (Table 2).
Table 1 Demographic data and background information

\begin{tabular}{|c|c|c|}
\hline & $\begin{array}{l}\text { Liothyronine } \\
\text { group } \\
(n=15)\end{array}$ & $\begin{array}{l}\text { Placebo } \\
\text { group } \\
(n=15)\end{array}$ \\
\hline Age, years: mean (s.d.) & $37.93(12.16)$ & $38.33(10.36)$ \\
\hline $\begin{array}{l}\text { Gender, } n \\
\text { Male } \\
\text { Female }\end{array}$ & $\begin{array}{l}8 \\
7\end{array}$ & $\begin{array}{l}7 \\
8\end{array}$ \\
\hline $\begin{array}{l}\text { Marital status, } n \\
\text { Single } \\
\text { Married } \\
\text { Divorced }\end{array}$ & $\begin{array}{l}7 \\
7 \\
1\end{array}$ & $\begin{array}{l}4 \\
9 \\
2\end{array}$ \\
\hline $\begin{array}{l}\text { Education } \\
\text { No formal education } \\
\text { Primary school } \\
\text { Secondary school } \\
\text { High school } \\
\text { University degree }\end{array}$ & $\begin{array}{l}1 \\
4 \\
5 \\
4 \\
1\end{array}$ & $\begin{array}{l}1 \\
4 \\
6 \\
3 \\
1\end{array}$ \\
\hline $\begin{array}{l}\text { Antidepressant medication } \\
\text { Selective serotonin reuptake } \\
\text { inhibitor } \\
\text { Tricyclic antidepressant } \\
\text { Trazodone } \\
\text { Bupropion }\end{array}$ & $\begin{array}{r}12 \\
3 \\
7 \\
0\end{array}$ & $\begin{array}{r}11 \\
2 \\
4 \\
2\end{array}$ \\
\hline $\begin{array}{l}\text { Number of previous episodes, } \\
\text { mean (s.d.) }\end{array}$ & $3.09(2.2)$ & $3.41(1.95)$ \\
\hline $\begin{array}{l}\text { Age at first episode, years: } \\
\text { mean (s.d.) }\end{array}$ & $32.34(12.23)$ & $33.47(13.85)$ \\
\hline
\end{tabular}

\section{Discussion}

Most of the evidence on the positive cognitive effect of add-on liothyronine to ECT has been described elsewhere. ${ }^{12-15}$ Although the exact mechanism of improving memory is not clear, one of the proposed theories is that administering liothyronine may decrease thyrotropinreleasing hormone, which has anticonvulsive effects. The lowered seizure threshold would then result in fewer stimulus charges per session, which may affect cognition and memory and less adversely. The results of our study showed that in all participants, ECT decreased the symptoms of depression and that cognitive performance was significantly higher in patients who received liothyronine compared with those who received a placebo. This effect became evident after the sixth session of ECT. No serious adverse effects were observed in either the liothyronine or the placebo group.

\section{Limitations}

There are a number of limitations to our study. The practice of ECT in Iran differs to that seen in high-income countries. In Mazandaran province severe depression in the adult population constitutes a major socioeconomic burden in addition to the known detrimental effects that mental illness can have on the family (such as stigma). The therapeutic emphasis is on rapid clinical recovery. Also, patients tend to be admitted for psychiatric care very late in the course of their illness when there is serious concern for their mental and physical health. In our study, the antidepressant medications prescribed for patients were selective serotonin reuptake inhibitors, trazodone, tricyclic 
Table 2 Statistical analysis of the results of depression and memory scales ${ }^{a}$

\begin{tabular}{|c|c|c|c|c|c|c|c|}
\hline & \multicolumn{3}{|c|}{ Mean (s.d.) } & \multicolumn{2}{|c|}{$\begin{array}{c}\text { Independent sample } \\
\text { t-test }\end{array}$} & \multicolumn{2}{|c|}{$\begin{array}{c}\text { Mann-Whitney } \\
\text { U-test }\end{array}$} \\
\hline & $\begin{array}{c}\text { Total } \\
(n=30)\end{array}$ & $\begin{array}{l}\text { Liothyronine } \\
\text { group }(n=15)\end{array}$ & $\begin{array}{l}\text { Placebo group } \\
\quad(n=15)\end{array}$ & d.f. & $P$ & $z$ & $P$ \\
\hline \multicolumn{8}{|c|}{ Hamilton Rating Scale for Depression } \\
\hline$T_{1}$ (before 1st ECT session) & $36.70(4.89)$ & $37.86(4.77)$ & $35.53(4.88)$ & 28 & 0.19 & -1.22 & 0.23 \\
\hline$T_{2}$ (after 3rd ECT session) & $24.06(7.16)$ & $23.73(8.31)$ & $24.40(6.08)$ & 28 & 0.80 & -0.56 & 0.59 \\
\hline$T_{3}$ (after 6th ECT session) & $16.20(6.97)$ & $13.40(6.55)$ & $19.00(6.41)$ & 28 & 0.025 & -2.25 & 0.024 \\
\hline \multicolumn{8}{|c|}{ Wechsler Memory Scale - Revised } \\
\hline$T_{1}$ (before 1st ECT session) & $73.60(18.43)$ & $76.26(19.70)$ & $70.93(17.33)$ & 28 & 0.43 & -0.83 & 0.41 \\
\hline$T_{3}$ (after 6th ECT session) & $80.20(17.65)$ & $87.00(18.22)$ & $73.40(14.64)$ & 28 & 0.033 & -2.03 & 0.041 \\
\hline
\end{tabular}

$E C T$, electroconvulsive therapy

a. Results in bold are significant at the $P \leqslant 0.05$ level.

antidepressants and bupropion, which are the main choices for treatment of depression locally. At the time of the research project there was a lack of availability of new generation antidepressants locally (for example mirtazapine and nefazodone). Other antidepressants such as venlafaxine, duloxetine and escitalopram were either extremely expensive, as they are not funded by the public sector, or difficult to find in private markets.

There are some major differences in the use of ECT as described in the current study to that considered standard practice in high-income countries. These are generally a lower threshold for prescribing ECT and using a more intense treatment regime (for example a higher initial stimulus charge and a frequency of up to three times per week for at least six sessions). This is to reduce the human cost (suicide or death as a result of dehydration and starvation) and the economic burden of severe depression on families, as quickly as possible. We acknowledge that these aspects of ECT practice are not totally in line with guidelines produced in high-income countries, ${ }^{26}$ but they have been adapted based on the experience of the mental health professionals to meet the needs of the local population.

We did not include patients who were older $(>60$ years old) because they were on several other medications for associated physical health problems, hence, making a concomitant prescription of liothyronine relatively unsafe. Also, it was decided not to include older individuals to avoid adversely affecting any underlying age-related cognitive difficulties, which could have been missed at initial assessments.

Although ECT can be used for severe treatmentresistant psychosis, mania and catatonia, patients with psychotic features were excluded from our study as the focus was on patients with severe debilitating depression presenting with serious suicidal ideation or attempts and poor food and fluid intake. We acknowledge that by doing this we excluded a considerable number of patients who may have potentially benefitted from ECT, but our aim was to concentrate on a diagnostically homogeneous sample of adult patients.

Other limitations of our study were the small sample size (resulting in a modest statistical significance) and the continuation of antidepressant therapy for the duration of the study. All patients were on therapeutic doses of antidepressant medication. Although no other statistical analysis (such as logistic regression) was used that would take account of the different doses of various antidepressant medications this, in our opinion, would not have adversely affected the outcome of the study as all eligible participants were entered into the study while already taking antidepressant medication and the dose was kept unchanged for the duration of the study. Also, individual patients needed administration of different stimulus charges relating to their own seizure threshold. We were unable to meaningfully take this into account in our statistical analysis.

We were also unable to investigate whether liothyronine might have had a beneficial effect on the subjective memory difficulties experienced by patients following a course of ECT. For practical reasons it was not possible to follow patients up in the community to find out about the lasting effect of this intervention.

\section{Further research}

In conclusion, judicious administration of $50 \mu \mathrm{g}$ per day of liothyronine during a course of ECT may decrease negative cognitive side-effects and improve mood in patients with severe depression. However, some important issues remain that require further investigation. Could the results of the current study be repeated in a research project with a larger sample size and in those with associated psychotic symptoms? For how long would a positive result persist? Could this combined approach have a favourable effect on the subjective memory problems experienced by patients long after receiving a course of ECT? Given the unjustifiably negative media publicity that ECT attracts (despite its proven life-saving efficacy on severe depression) and considering the low cost and relatively safe use of liothyronine, it would be advisable to at least explore the above issues further in future research projects in order to gain a better understanding of the beneficial effects of add-on thyroid hormone on the cognitive adverse effects of ECT.

\section{Funding}

This study was fully funded by Mazandaran University of Medical Sciences

\section{Acknowledgements}

We are grateful to our patients and their families who kindly agreed to participate in this study. Special thanks go to Professor Mehran Zarghami, 
clinical director and lead clinician of the department and all our colleagues in Zare Hospital and Mazandaran University who helped us carry out this research project. We also thank S. Jafari, the ward psychologist, who carried out the HRSD and WMS-R assessments.

\section{About the authors}

DrAbbas Masoudzadeh (MD) is an associate professor in the Department of Psychiatry and Psychiatry \& Behavioral Sciences Research Center at Mazandaran University of Medical Sciences, Sari, Iran. Dr Seyyed Taha Yahyavi (MD) is a senior resident in the Department of Psychiatry at Mazandaran University of Medical Sciences. Dr Hooman Rashidi (MD) is a researcher in the Department of Psychiatry at Mazandaran University of Medical Sciences. Dr Reza Ali Mohammadpour (PhD) is an associate professor in the Department of Biostatistics at Mazandaran University of Medical Sciences. Dr Reza Kiani (MD, Dip, MRCPsych) is a consultant in adult learning disability services at Leicester Frith Hospital, UK.

\section{References}

1 Antunes PB, Rosa MA, Belmonte-de-Abreu PS, Lobato MI, Fleck MP. Electroconvulsive therapy in major depression: current aspects. Rev Bras Psiquiatr 2009; 31 (suppl 1): S26-33.

2 Semkovska M, McLoughlin DM. Objective cognitive performance associated with electroconvulsive therapy for depression: a systematic review and meta-analysis. Biol Psychiatry 2010; 68: 568-77.

3 Ingram A, Saling MM, Schweitzer I. Cognitive side effects of brief pulse electroconvulsive therapy: a review. J ECT 2008; 24: 3-9.

4 Prudic J, Peyser S, Sackeim HA. Subjective memory complaints: a review of patient self-assessment of memory after electroconvulsive therapy. J ECT 2000; 16: 121-32.

5 McCall WV, Prudic J, Olfson M, Sackeim H. Health-related quality of life following ECT in a large community sample. J Affect Disord 2006; 90: 269-74.

6 Prudic J. Strategies to minimize cognitive side effects with ECT: aspects of ECT technique. J ECT 2008; 24: 46-51.

7 Semkovska M, Keane D, Babalola O, McLoughlin DM. Unilateral briefpulse electroconvulsive therapy and cognition: effects of electrode placement, stimulus dosage and time. J Psychiatr Res 2011; 45: 770-80.

8 Eschweiler GW, Vonthein R, Bode R, Huell M, Conca A, Peters O, et al. Clinical efficacy and cognitive side effects of bifrontal versus right unilateral electroconvulsive therapy (ECT): a short-term randomised controlled trial in pharmaco-resistant major depression. J Affect Disord 2007; 101: 149-57.

9 Sackeim HA, Prudic J, Devanand DP, Nobler MS, Lisanby SH, Peyser S, et al. A prospective, randomized, double-blind comparison of bilateral and right unilateral electroconvulsive therapy at different stimulus intensities. Arch Gen Psychiatry 2000; 57: 425-34.

10 Sackeim HA, Dillingham EM, Prudic J, Cooper T, McCall WV, Rosenquist $P$, et al. Effect of concomitant pharmacotherapy on electroconvulsive therapy outcomes: short-term efficacy and adverse effects. Arch Gen Psychiatry 2009; 66: 729-37.

11 Krueger RB, Sackeim HA, Gamzu ER. Pharmacological treatment of the cognitive side effects of ECT: a review. Psychopharmacol Bull 1992; 28: 409-24.

12 Stern RA, Steketee MC, Durr AL, Prange AJ, Golden RN. Combined use of thyroid hormone and ECT. Convuls Ther 1993; 9: 285-92.

13 Tremont G, Stern RA. Use of thyroid hormone to diminish the cognitive side effects of psychiatric treatment. Psychopharmacol Bull 1997; 33 273-80.

14 Stern RA, Nevels CT, Shelhorse ME, Prohaska ML, Mason GA, Prange Jr AJ. Antidepressant and memory effects of combined thyroid hormone treatment and electroconvulsive therapy: preliminary findings. Biol Psychiatry 1991; 30: 623-7.

15 Tremont G, Stern RA. Minimizing the cognitive effects of lithium therapy and electroconvulsive therapy using thyroid hormone. Int $J$ Neuropsychopharmacol 2000; 3: 175-86.

16 Hamidia A, Ghadiri M, Afkham Ebrahimi A. Comparison of memory impairment due to electroconvulsive therapy in depressed patients receiving Liothyronine and vitamin B12. Iran J Psychiatry Clin Psychol 2006; 12: 16-20.

17 Taubøll E, Gjerstad L, Stokke KT, Lundervold A, Telle B. Effects of electroconvulsive therapy on thyroid function parameters. Psychoneuroendocrinology 1987; 12: 349-54

18 Motta E, Ostrowska Z, Kazibutowska Z, Paluch M, Ponka J, Goba A. The effect of a single electroconvulsive shock on pituitary-thyroid-adrenalgonadal axis function in men with severe depression-preliminary report. Psychiatr Pol 2005; 39: 469-79.

19 Esel E, Turan T, Kula M, Reyhancan M, Gonul A, Basturk M, et al. Effects of electroconvulsive therapy on hypothalamic-pituitary-thyroid axis activity in depressed patients. Prog Neuropsychopharmacol Biol Psychiatry 2002; 26: 1171-5.

20 Esel E, Kilic C, Kula M, Basturk M, Ozsoy S, Turan T, et al. Effects of electroconvulsive therapy on the thyrotropin-releasing hormone test in patients with depression. J ECT 2004; 20: 248-53.

21 Sadock BJ, Sadock VA, Ruiz P. Kaplan \& Sadock's Comprehensive Textbook of Psychiatry (9th edn). Lippincott Williams \& Wilkins, 2009.

22 Zarghami M, Khalilian A. Deliberate self-burning in Mazandaran, Iran Burns 2002; 28: 115-9.

23 American Psychiatric Association. Diagnostic and Statistical Manual of Mental Disorders (4th edn, text revision) (DSM-IV-TR). APA, 2000.

24 Hamilton M. A rating scale for depression. J Neurol Neurosurg Psychiatry 1960; 23: 56-62.

25 Orangi M, Atefvahid MK, Ashayeri H. Standardization of the Revised Wechsler Memory Scale in Shiraz. Iran J Psychiatry Clin Psychol 2002; 7 56-66.

26 Scott AIF. The ECT Handbook (2nd edn). The Third Report of the Royal College of Psychiatrists' Special Committee on ECT (Council Report CR128). Royal College of Psychiatrists, 2004. 